\title{
Comparison of Efficiency between Pre-storage and Post-storage filtration by Leukoreduction Blood Filter
}

\author{
Geon Sik Shin ${ }^{1,2, \$}$, Bohee Kim ${ }^{1, \S}$, Sung Hoon Kim ${ }^{1}$, Ki-Jong Rhee ${ }^{1}$ and Yoon Suk Kim ${ }^{1, \uparrow}$ \\ ${ }^{I}$ Department of Biomedical Laboratory Science, College of Health Sciences, Yonsei University, \\ Wonju, Gangwon-do 26493, Korea \\ ${ }^{2}$ Blood Transfusion Research Institute, Korean Red Cross, Wonju, Gangwon-do 26465, Korea
}

\begin{abstract}
Leukocytes in blood components are involved in diverse adverse transfusion reactions such as febrile non-hemolytic transfusion reactions. Therefore, leukocyte reduction is required to reduce these adverse reactions. The objective of this study was to compare the efficiency of pre-storage filtration and post-storage filtration. Filtration time, residual leukocyte count, RBC recovery, and hemolysis were assessed after pre-storage or post-storage filtration. Compared to pre-storage filtration, filtration time was prolonged and hemolysis was dramatically increased when post-storage filtration was performed. Residual leukocytes count and RBC recovery after post-storage filtration were similar with those obtained after pre-storage filtration. These results suggest that pre-storage filtration has better efficiency than post-storage filtration. These are thought to contribute to the production of better quality of leukoreduction blood components.
\end{abstract}

Key Words: Leukoreduction blood filter, Adverse transfusion reaction, Pre-storage filtration, Filtration efficiency

\section{서 론}

수혈의 필요성이 증가하고 있어 혈액제제의 수요는 계속 증가하고 있다(Menitove et al., 1982). 이러한 혈액제 제들에 있는 백혈구에 의해 이식편대숙주병(graft-vs-host disease) 등 다양한 수혈부작용(transfusion reaction)이 유발 된다고 알려져 있다(Evans and Gordon, 1974; Herzig et al., 1975). 이를 예방하기 위해 백혈구를 제거한 혈액제제에 대한 연구가 진행되어 왔다(Saarinen et al., 1990; Lane et al., 1992; Bruil et al., 1995; Kwon, 1995; Zoon, 1996; Vamvakas, 2006). 그 결과 많은 국가에서 헌혈 후 백혈구를 제거하는 정책(Universal Leukocyte Reduction; ULR)이 시행 중이다
(Engelfriet et al., 2001; Vamvakas and Blajchman, 2001; Bassuni et al., 2008). 현재 백혈구제거 혈액제제의 사용이 꾸준히 증가하고 있다.

백혈구제거 평가 기준으로 미국 Food and Drug Administration (FDA) 및 유럽 Council of Europe (CE)의 기준 등 이 있는데 $\mathrm{FDA}$ 기준은 잔여백혈구 수 $5.0 \times 10^{6} / \mathrm{unit}$ 미 만(Guidances, 2012), 적혈구 회수율 $85 \%$ 이상이며 $\mathrm{CE}$ 기 준은 잔여백혈구 수 $1.0 \times 10^{6} /$ unit 미만(Medicines, 2013), 적혈구 회수율은 $85 \%$ 이상이다. 적혈구 용혈률은 $\mathrm{FDA}$ 기 준 $1 \%$ 미만, $\mathrm{CE}$ 기준 $0.8 \%$ 미만이다.

현재 국내에서는 백혈구제거 혈액제제 제조 시에 저장 전 여과법과 저장 후 여과법으로 백혈구를 제거하고 있으 며 두 여과법의 사용률은 비슷하다고 보고되어 있다. 저

*Received: June 22, 2017 / Revised: June 27, 2017 / Accepted: June 28, 2017

$\S_{\text {These authors contributed equally to this manuscript }}$

${ }^{\dagger}$ Corresponding author: Yoon Suk Kim. Department of Biomedical Laboratory Science, College of Health Sciences, Yonsei University,Wonju, Gwangwon 26493, Korea.

Tel: +82-33-760-2860, Fax:+82-33-760-2195, e-mail: yoonsukkim@yonsei.ac.kr

(C) The Korean Society for Biomedical Laboratory Sciences. All rights reserved.

(c) This is an Open Access article distributed under the terms of the Creative Commons Attribution Non-Commercial License (http://creativecommons.org/licenses/by-nc/3.0/) which permits unrestricted non-commercial use, distribution, and reproduction in any medium, provided the original work is properly cited. 
장 전 여과는 의료기관에 공급하기 전에 혈액원에서 채혈 후 8시간 내에 백혈구를 제거하여 백혈구제거 혈액제제를 제조하는 것을 의미하며, 저장 후 여과는 혈액원이 여과 하지 않은 혈액제제를 공급 후 의료기관에서 수혈 직전에 백혈구를 제거하는 것을 말한다. 최근과 같은 한정된 혈 액수급 환경에서 더욱 효율적인 수혈을 위해서는 저장 전 여과법과 저장 후 여과법의 여과 효율을 비교 분석하여 고효율의 여과법을 제시하여 사용을 권장하는 것이 필요 하다. 본 연구에서는 저장 전 여과와 저장 후 여과의 여과 효율을 비교 분석하여 저장 전 여과법이 저장 후 여과법 보다 여과 효율이 더 우수함을 확인하였고, 이 결과를 토 대로 저장 전 여과법 사용을 권장하여 보다 질 좋은 백혈 구제거 혈액제제 제조에 기여하고자 한다.

\section{재료 및 방법}

\section{혈액여과 및 여과시간 측정}

본 실험은 대한적십자사 생명윤리심의 승인을 득한 후 (안전관리팀-513, 2017. 02. 08) 실시하였다. 채혈 후 4시간 이내에 농축적혈구를 제제하였고 코오롱 인더스트리(주) 에서 개발된 농축적혈구용 백혈구제거 혈액필터를 이용하 여 여과를 실시하였다. 여과시점 효율성 비교연구를 위해 저장 전 여과는 채혈 후 8시간 이내에 여과를 실시하였으 며, 저장 후 여과는 농축적혈구 제조 후 4 일 동안 $44^{\circ} \mathrm{C}$ 로 보관한 농축적혈구제제로 여과를 실시하였다. 여과시간은 여과시작부터 혈액백 내 혈액이 모두 비워지기까지의 시 간으로 정하여 측정하였다.

\section{잔여백혈구 수 및 백혈구 제거율 측정, 계산}

잔여백혈구 수는 Fluorescence Activated Cell Sorter (FACS) 장비를 이용하여 LeucoCOUNT kit (BD bioscience, San Jose, $\mathrm{CA}, \mathrm{USA}$ )를 사용한 Bead-based flow cytometry 검사법으로 측정하였다. TruCOUNT tube에 검체 $100 \mu \mathrm{L}$ 를 첨가 후 LeucoCOUNT reagent $400 \mu \mathrm{L}$ 를 첨가하여 5 분간 반응 후 FACSCanto II (BD bioscience, San Jose, CA, USA) 장비를 이용하여 Bead events 수(R1)와 WBC events 수(R2)를 각 각 측정하여 아래의 공식에 있는 식에 의해 여과 후 잔 여백혈구 수와 백혈구 제거율을 계산하였다(Barclay et al., 1998; Gomez-Arbones et al., 1999).

$$
\begin{gathered}
\text { 잔여백혈구 수 } \\
(\text { 개 } / \mu \mathrm{l})
\end{gathered}=\frac{\text { 백혈구 수 }(\mathrm{R} 2)}{\operatorname{Bead} \text { 수 }(\mathrm{R} 1)} \times \frac{\text { 총 } \mathrm{Bead} \text { 수 }}{\text { 혈액량 }(\mu \mathrm{L})}
$$

백혈구 제거율 $(\%)=100-\frac{\text { (여과 후 백혈구 수) }}{\text { (여과 전 백혈구 수) }} \times 100$

\section{적혈구 회수율, 적혈구 용혈률 측정}

저장 전 여과와 저장 후 여과 전·후에 혈액검체 $1 \mathrm{~mL}$ 을 채취하여 적혈구 수와 적혈구 용적률 $(\mathrm{Hct})$ 을 자동혈구 계산기(KX-21N, Sysmex, Kobe, Japan)로 측정하였다. 적혈 구 회수율은 아래의 공식을 이용하여 산출하였다. 혈장 혈색소 $(\mathrm{Hb})$ 측정을 위하여 혈액백에서 채취한 $2 \mathrm{~mL}$ 혈액 검체를 $3,000 \mathrm{rpm} \times 10$ 분간 원심분리 후 분리한 혈장 $200 \mu \mathrm{L}$ 와 $\mathrm{Na}_{2} \mathrm{CO}_{3}$ 용액 $2 \mathrm{~mL}$ 을 혼합 후 $415 \mathrm{~nm}, 450 \mathrm{~nm}$, $700 \mathrm{~nm}$ 파장에서 각각 흡광도를 측정하였다. 혈장 혈색소 농도와 적혈구 용혈률은 아래의 공식을 이용하여 계산하 였다(Fairbanks et al., 1992).

$$
\text { 적혈구 회수율 }(\%)=\frac{\begin{array}{l}
\text { (여과 후 용량) } \times \\
(\text { 여과 후 } \mathrm{Hct})
\end{array}}{\begin{array}{l}
\text { (여과 전 용량) }) \times \\
(\text { 여과 후 } \mathrm{Hct})
\end{array}} \times 100
$$

혈장 $\mathrm{Hb}(\mathrm{mg} / \mathrm{dL})=\left(155.0 \times \mathrm{A}_{415}\right)-\left(130.0 \times \mathrm{A}_{450}\right)-$ $\left(124.0 \times \mathrm{A}_{700}\right)$

적혈구 용혈률 $(\%)=\frac{\text { 혈장 } \mathrm{Hb} \times(100-\% \mathrm{Hct})}{\text { Total } \mathrm{Hb}} \times 100$

\section{결 과}

\section{저장 전 여과법과 저장 후 여과법의 여과시간 비교.}

백혈구제거 농축적혈구제제는 저장 전에 백혈구를 제거 하거나 저장 후에 백혈구를 제거하는 두 가지 방법으로 제조한다. 최근과 같이 혈액수급 상황이 점차로 안 좋아 지는 상황에서 여과시점에 따른 여과 효율을 비교연구하 여 보다 효율적인 여과시점을 확인하는 것은 제한된 혈액 을 보다 효과적으로 사용하는데 매우 중요하다. 따라서 본 연구에서는 백혈구제거 혈액필터를 이용하여 저장 전 여과와 저장 후 여과의 효율을 비교 평가하였다. 채혈 후 8 시간 이내 여과를 저장 전 여과로 채혈 후 4 일간 냉장 보관된 농축적혈구제제의 여과를 저장 후 여과로 하여 연 구를 진행하였다. 
Table 1. Comparison of parameters evaluated after post-storage and pre-storage filtration

\begin{tabular}{|c|c|c|c|}
\hline \multicolumn{2}{|c|}{ Parameters } & \multirow{2}{*}{$\begin{array}{c}\begin{array}{c}\text { Post-storage } \\
\text { filtration } \\
(\mathrm{n}=10)\end{array} \\
59 \mathrm{~m} 44 \mathrm{~s}\end{array}$} & \multirow{2}{*}{$\begin{array}{c}\begin{array}{c}\text { Pre-storage } \\
\text { filtration } \\
(\mathrm{n}=10)\end{array} \\
12 \mathrm{~m}\end{array}$} \\
\hline & Ave & & \\
\hline \multirow[t]{2}{*}{ Filtration time } & Min & $29 \mathrm{~m} 50 \mathrm{~s}$ & $7 \mathrm{~m} \mathrm{16s}$ \\
\hline & Max & $107 \mathrm{~m} 30 \mathrm{~s}$ & $16 \mathrm{~m} 33 \mathrm{~s}$ \\
\hline \multirow{3}{*}{$\begin{array}{l}\text { Residual } \\
\text { leukocyte } \\
\left(\times 10^{6} / \text { unit }\right)\end{array}$} & Ave & 0.003 & 0.098 \\
\hline & Min & 0 & 0 \\
\hline & Max & 0.03 & 0.2 \\
\hline \multirow{3}{*}{$\begin{array}{l}\text { Leukoreduction } \\
(\%)\end{array}$} & Ave & 99.999 & 99.996 \\
\hline & Min & 99.999 & 99.989 \\
\hline & Max & 100 & 100 \\
\hline \multirow{3}{*}{$\begin{array}{l}\text { RBC recovery } \\
(\%)\end{array}$} & Ave & 88.4 & 90.6 \\
\hline & Min & 85.3 & 88.2 \\
\hline & Max & 90.5 & 92.3 \\
\hline \multirow{3}{*}{$\begin{array}{l}\text { Hemolysis }(\%) \\
\text { at day } 0 \\
\text { after filtration }{ }^{\dagger}\end{array}$} & Ave & 0.3 & 0.02 \\
\hline & Min & 0.21 & 0.01 \\
\hline & Max & 0.53 & 0.04 \\
\hline \multirow{3}{*}{$\begin{array}{l}\text { Hemolysis }(\%) \\
\text { at day } 28 \\
\text { after filtration }\end{array}$} & Ave & 0.69 & 0.09 \\
\hline & Min & 0.51 & 0.06 \\
\hline & Max & 1.01 & 0.15 \\
\hline
\end{tabular}

*For this study to compare the efficacy of pre-storage filtration and post-storage filtration, domestic filters, FINECELL developed by KOLON INDUSTRIES, INC., (Gumi, Korea) were used as test filters.

$\dagger$ assessed immediately after filtration.

*assessed at day 35 after filtration.

농축적혈구는 본래 $4^{\circ} \mathrm{C}$ 냉장상태에서 보관하지만 백혈 구제거를 위한 여과는 상온에서 실시하고 있다. 따라서 여과시간이 길어지면 상온에 노출되는 시간이 증가하여 적혈구 손상을 야기할 가능성이 있어 여과시간을 평가하 는 것이 중요하다. 따라서 저장 전 여과와 저장 후 여과의 여과시간을 먼저 평가하였다. Table 1과 Fig. 1에서 보는 바 와 같이 여과시간은 저장 전 여과의 경우 평균 12 분, 최대 16 분 33 초, 최소 7 분 16 초였으며, 저장 후 여과의 경우 평 균 59 분 44 초, 최대 107 분 30 초, 최소 29 분 50 초였다. 이 결과를 통해 저장 전 여과가 저장 후 여과에 비해 여과시 간이 짧은 것을 확인할 수 있었으며, 이를 통해 저장 전 여과 중에 적혈구 손상 가능성이 저장 후 여과보다 적을 것임을 추론할 수 있었다.

\section{저장 전 여과법과 저장 후 여과법의 잔여백혈구 수 비교}

다음은 저장시점에 따른 잔여백혈구 수를 확인하였다. 결과(Table 1, Fig. 2)에서 보는 바와 같이 저장 전 여과의 경우 잔여백혈구 수는 평균 $0.098 \times 10^{6}$ unit, 최대 $0.2 \times$ $10 \%$ unit, 최소 $0 \times 10 \%$ unit였으며, 저장 후 여과의 경우는 평균 $0.003 \times 10^{6} /$ unit, 최대 $0.03 \times 10^{6} /$ unit, 최소 $0 \times$ $10^{6} / \mathrm{unit}$ 로 측정되어 두 방법 모두 유럽 기준 $\left(<1 \times 10^{6} \%\right.$ unit) 및 미국 기준 $\left(<5 \times 10^{6} / \mathrm{unit}\right)$ 을 만족하는 백혈구 제 거능을 보였다. 저장 전 여과의 백혈구 제거율은 평균 $99.996 \%$, 최대 $100 \%$, 최소 $99.989 \%$ 였으며, 저장 후 여과 의 경우는 평균 $99.999 \%$, 최대 $100 \%$, 최소 $99.999 \%$ 로 계 산되었다(Table 1). 이 결과를 통해 저장 전 여과와 저장 후 여과의 백혈구 제거율은 비슷함을 확인할 수 있었다.

\section{저장 전 여과법과 저장 후 적혈구 회수율 비교.}

적혈구 회수율은 결과(Table 1, Fig. 3)에서 보는 바와 같 이 저장 전 여과의 경우 평균 $90.6 \%$, 최대 $92.3 \%$, 최소 $88.2 \%$ 였고 저장 후 여과의 경우 평균 $88.4 \%$, 최대 $90.5 \%$, 최소 $85.3 \%$ 여서 두 여과법 모두 국제기준 $(\geqq 85 \%)$ 을 만 족하는 적혈구 회수율을 보였다(Table 3, Fig. 3). 이 결과로 저장 전 여과와 저장 후 여과에서 적혈구 회수율은 큰 차 이가 없음을 확인하였다.

\section{저장 전 여과법과 저장 후 적혈구 용혈률 비교.}

다음으로 적혈구 용혈률을 비교 확인하였는데, 결과 (Table 1, Fig. 4)에서 보는 바와 같이 저장 전 여과법으로 여과한 직후의 적혈구 용혈률은 평균 $0.02 \%$, 최대 $0.04 \%$, 최소 $0.01 \%$ 였으며, 저장 후 여과법으로 여과한 직후의 적 혈구 용혈률은 평균 $0.3 \%$, 최대 $0.53 \%$, 최소 $0.21 \%$ 였다. 저장 전 여과법으로 여과한 후 28 일이 지나 적혈구 용혈 률을 측정한 결과는 평균 $0.09 \%$, 최대 $0.15 \%$, 최소 $0.06 \%$ 였으며, 저장 후 여과법으로 여과 후 28 일이 지나 측정한 적혈구 용혈률은 평균 $0.69 \%$, 최대 $1.01 \%$, 최소 $0.51 \%$ 였 다. 저장 전 여과와 저장 후 여과에 의한 적혈구 용혈률은 여과 직후에 평가 시 15 배 정도의 차이(평균 $0.02 \%$ 대 평 균 $0.3 \%$ )를 보였다. 저장 후 여과법으로 여과 후 28 일이 지나 측정한 적혈구 용혈률 평균(약 $0.7 \%)$ 은 유럽 $<0.8 \%)$ 과 미국 제한기준 $(<1 \%)$ 에 가까운 근사치를 나타냈으며, 1 개의 실험군 혈액은 국제적 제한기준을 초과하는 $1.01 \%$ 의 적혈구 용혈률을 보였다(Table 1, Fig. 4). 이러한 결과를 통하여 저장 전 여과가 저장 후 여과에 비해 적혈구 용혈 
A

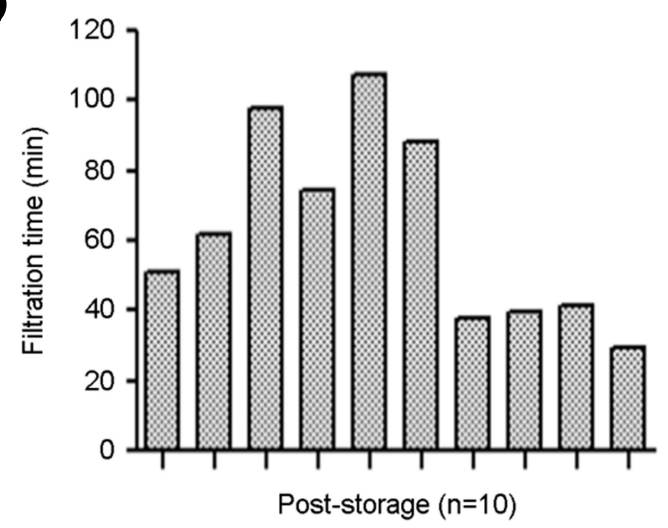

B

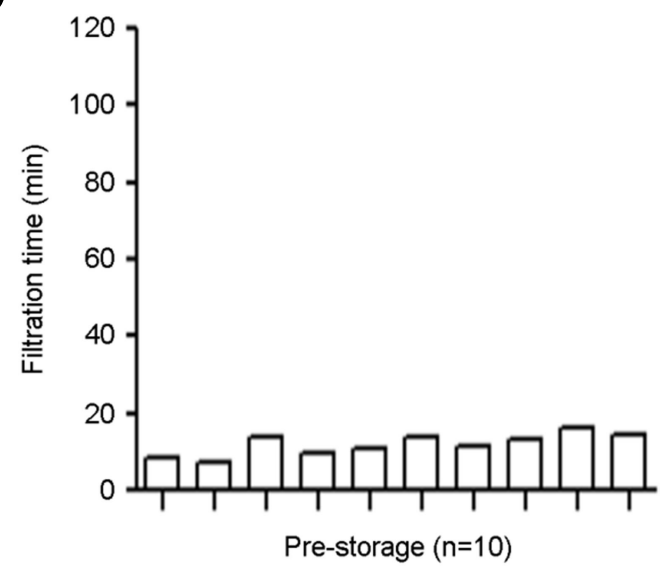

C

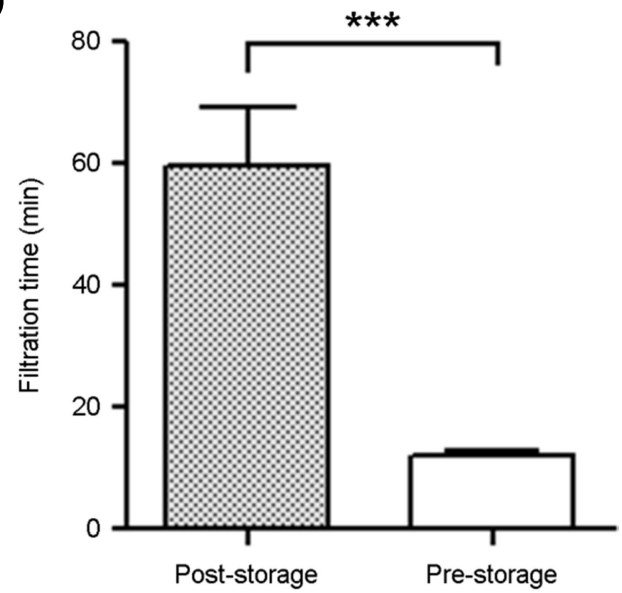

Fig. 1. Comparison of filtration time between post-storage and pre-storage filtration. Filtering for leukoreduction was carried out at room temperature within 8 hours of blood collection for prestorage filtration or at day 4 after blood collection for post-storage filtration. (A) Filtration time assessed after post-storage filtration $(\mathrm{n}=10)$, (B) Filtration time assessed after pre-storage filtration $(\mathrm{n}=10),(\mathrm{C})$ Comparison of filtration time between post-storage filtration $(\mathrm{n}=10)$ and pre-storage filtration $(\mathrm{n}=10)$. Data are expressed as the mean $\pm \mathrm{SD}$. $P$-values were determined by the Student's $t$-test $(* * * P<0.001)$.
A

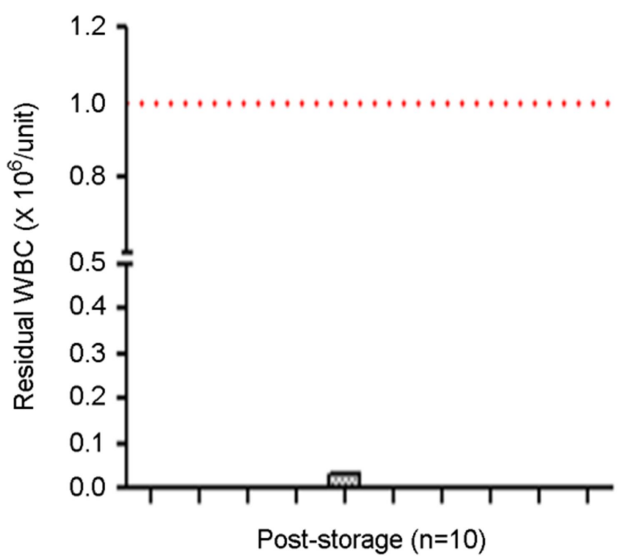

B

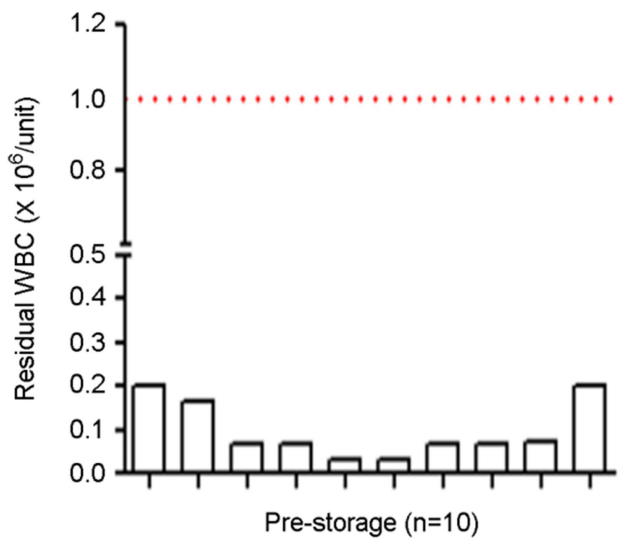

C

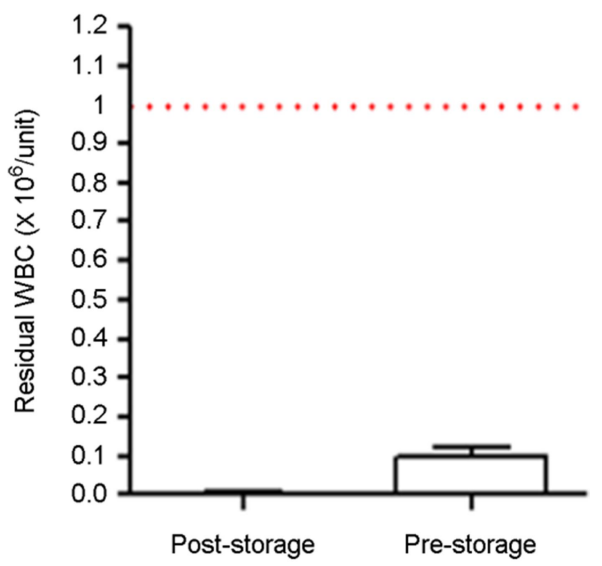

Fig. 2. Comparison of residual leukocyte count between poststorage and pre-storage filtration. Residual leukocyte count was measured by bead-based flow cytometry. Filtration was carried out at room temperature at day 4 after blood collection for post-storage filtration. (A) Residual leukocyte count evaluated after post-storage filtration $(\mathrm{n}=10)$. (B) Residual leukocyte count evaluated after prestorage filtration $(\mathrm{n}=10)$. (C) Comparison of residual leukocyte count between post-storage filtration $(n=10)$ and pre-storage filtration $(n=10)$. Data are expressed as the mean \pm SD. Dashed lines represent $\mathrm{CE}$ guideline $\left(<1.0 \times 10^{6} /\right.$ unit $)$ for residual leukocyte count. 


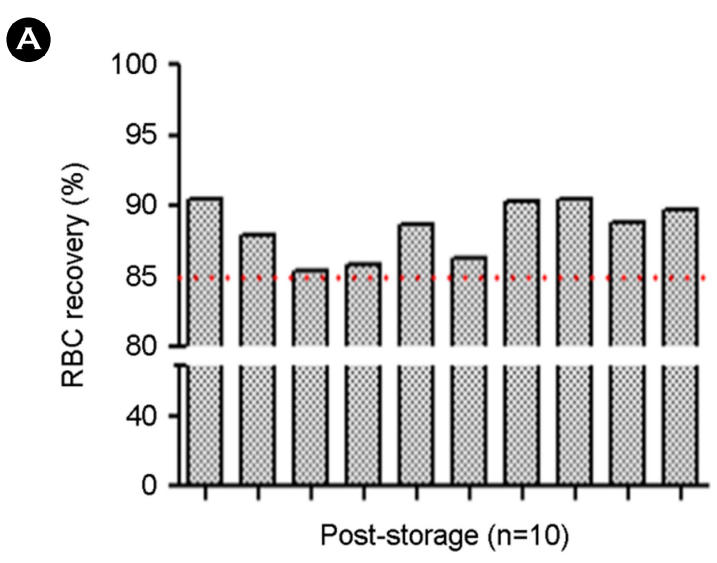

B

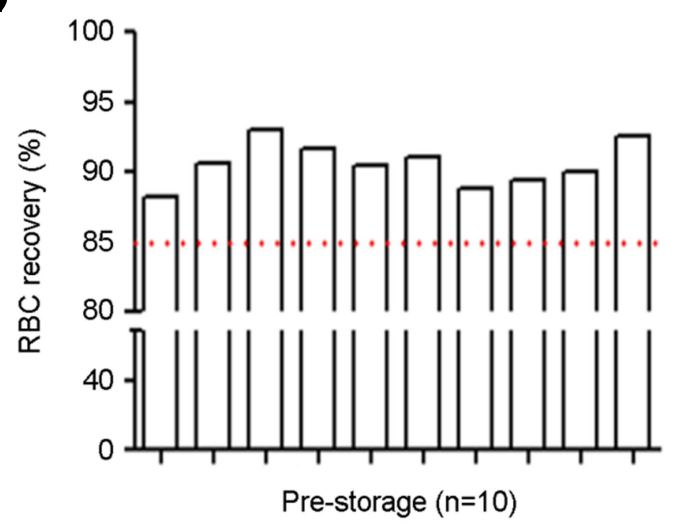

C

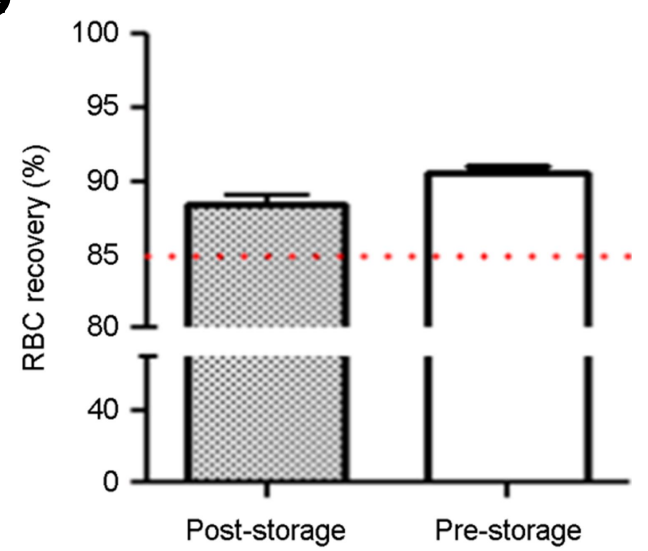

Fig. 3. Comparison of RBC recovery between post-storage and pre-storage filtration. $\mathrm{RBC}$ count and hematocrit were measured by Automated Hematology Analyzer. RBC recovery was calculated from the $\mathrm{RBC}$ count and hematocrit according to the formula described in Materials and methods. (A) RBC recovery assessed after post-storage filtration $(n=10)$. (B) RBC recovery assessed after pre-storage filtration $(n=10)$. (C) Comparison of $R B C$ recovery between post-storage filtration $(\mathrm{n}=10)$ and pre-storage filtration $(\mathrm{n}=10)$. Data are expressed as the mean $\pm \mathrm{SD}$. Dashed lines represent $\mathrm{CE}$ guideline ( $\geqq 85 \%$ ) for $\mathrm{RBC}$ recovery.
이 적은 것을 확인할 수 있었고, 저장 전 여과를 하는 것 이 적혈구에 손상을 적게 주어 장시간 경과 후(28일) 확인 했을 때 저장 후 여과의 경우보다 적혈구 용혈이 적은 것 을 확인하게 되어 적혈구 안정도를 위해서는 저장 전 여 과가 더 좋은 방법임을 추론할 수 있었다.

\section{고 찰}

해외에서는 혈액의 저장 전 백혈구제거가 여러 면에서 더 유용하다고 보고되고 있다(King et al., 2004; Yazer et al., 2004; Bassuni et al., 2008). 저장 후 여과는 여러 단위의 혈액을 수혈하는 경우 규정된 단위마다 필터를 교환해야 하는 번거로움이 있으며 이러한 필터교환 시와 여과 시에 오염의 위험이 더 크다. 혈액제제에서 저장 전에 백혈구 를 제거하는 경우, 저장 후 백혈구 제거 시보다 백혈구에 서 분비하는 싸이토카인과 같은 체액성 물질에 의한 부작 용을 줄일 수 있다. 또한 혈액보관 시 파괴되는 백혈구 파 편에 의한 동종면역 빈도도 감소한다고 보고되어 있다. 따라서 모든 ULR 도입국가는 저장 전 여과를 실시하고 있다. 반면 국내에서는 저장 전 여과와 저장 후 여과 두 방법 모두 백혈구 제거에 사용되고 있다. 따라서 저장 전 여과와 저장 후 여과를 비교 분석하여 더 효율적인 여과 법을 확인하고 이를 권장하는 것이 혈액관련정책에서 매 우 중요하다고 판단되어 본 연구에서는 여과시점에 따른 여과 효율성 비교연구를 진행하였다.

현재 혈액원에서 저장 전 여과 시 채혈 후 8 시간 이내 에 실시하기 때문에 채혈 후 8시간 이내 여과를 저장 전 여과로 규정하였다. 또한 의료기관이 혈액을 직접 여과 후 수혈할 목적으로 혈액원으로부터 여과하지 않은 혈액을 공급받을 경우, 보통 채혈 후 4일이 경과한 혈액을 공급받 기 때문에 채혈 후 4 일 경과한 혈액 여과를 저장 후 여과 로 규정하여 본 연구를 진행하였다. 먼저 저장 전 여과와 저장 후 여과 시 소요되는 시간을 평가한 결과 저장 후 여과의 여과시간이 저장 전 여과시간보다 약 40 분 이상 증가함을 확인하였다(Table 1, Fig. 1). 따라서 저장 후 여과 시 상온에서의 여과시간이 증가하여 적혈구 활성도에 좋 지 않은 영향을 미칠 것으로 추측된다. 또한 저장 후 여 과의 적혈구 용혈률이 저장 전 여과의 적혈구 용혈률보다 높은 수치를 보였다(Table 1, Fig. 4). 특히, 저장 후 여과의 경우 여과한지 28 일이 지난 후 적혈구 용혈률은 국제 제 한기준 $(0.8 \%$ 미만)에 근접한 용혈률을 나타냈으며 그 중 1 개 실험군에서는 적혈구 용혈률 $1.01 \%$ 로 국제적인 제한 
A

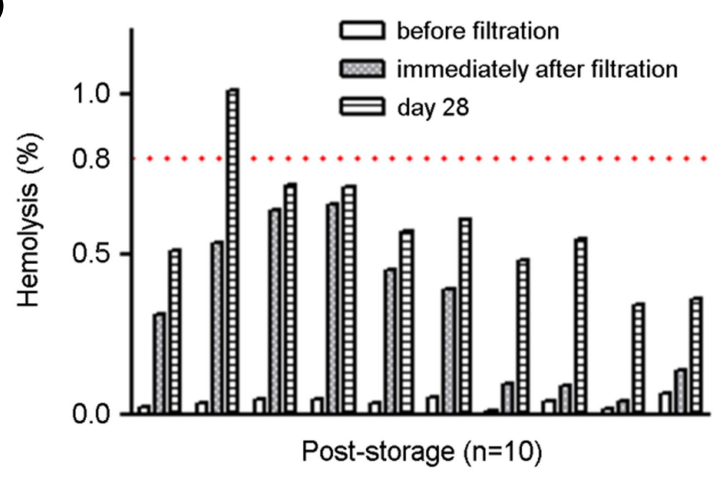

C

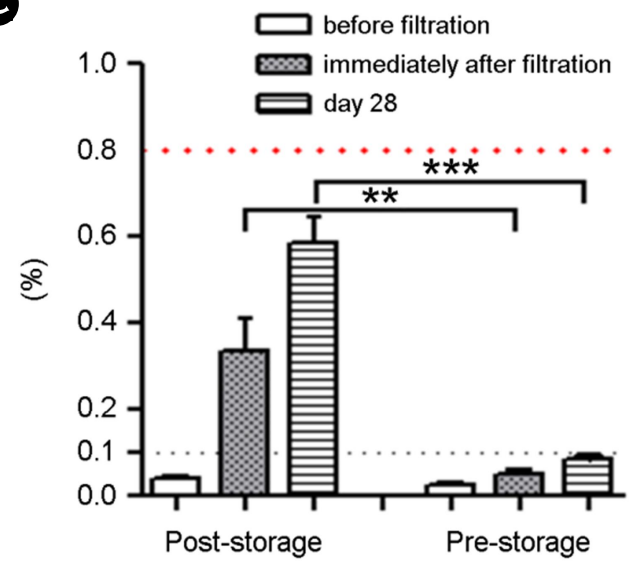

기준을 초과하는 결과를 보였다(Fig. 4). 이러한 결과를 통 하여 저장 후 여과가 저장 전 여과에 비해 적혈구 용혈이 증가함을 확인할 수 있었다. 결과적으로 백혈구제거를 위 한 농축적혈구 여과 시 저장 전 여과를 하는 것이 적혈구 의 안정도를 위해서 더 효율적이라는 것을 다시 한번 확 인할 수 있었다.

본 연구를 통해 저장 후 여과보다 저장 전 여과가 적혈 구 안정도를 더 잘 유지한다는 사실을 확인하였는데 이러 한 결과는 향후 백혈구제거 농축적혈구제제 제조 시 저장 전 여과를 실시할 것을 권장하는데 기초자료로 이용할 수 있을 것으로 생각한다.

\section{CONFLICT OF INTEREST}

The authors have no conflicts of interest to disclose.

\section{REFERENCES}

Barclay R, Walker B, Allan R, Reid C, Duffin E, Kane E, Turner
B

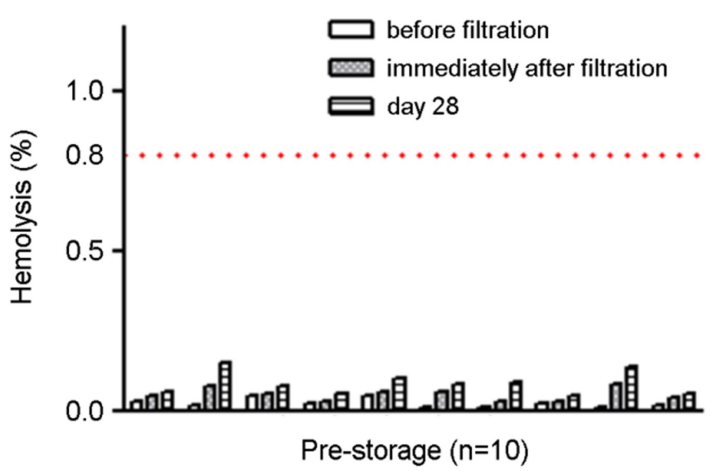

Fig. 4. Comparison of hemolysis between post-storage and prestorage filtration. Filtered $\mathrm{RBC}$ units were stored at $1 \sim 6^{\circ} \mathrm{C}$ for 28 days. To calculate the hemolysis, plasma hemoglobin was measured before filtration, immediately after filtration, and at day 28 after filtration. (A) Hemolysis assessed after post-storage filtration $(n=10)$. (B) Hemolysis assessed after pre-storage filtration $(n=10)$. (C) Comparison of hemolysis between post-storage filtration $(n=10)$ and pre-storage filtration $(n=10)$. Data are expressed as the mean \pm SD. $P$-values were determined by the Student's $t$-test $(* * P<0.01$, $* * * P<0.001)$. Dashed lines represent CE guideline $(<0.8 \%)$ for hemolysis.

M. Flow cytometric determination of residual leucocytes in filter-depleted blood products: an evaluation of BectonDickinson's LeucoCOUNT system. Transfusion Science. 1998. 19: $399-403$

Bassuni WY, Blajchman MA, Al-Moshary MA. Why implement universal leukoreduction? Hematology/Oncology and Stem Cell Therapy. 2008. 1: 106-123.

Bruil A, Beugeling T, Feijen J, van Aken WG. The mechanisms of leukocyte removal by filtration. Transfusion Medicine Reviews. 1995. 9: 145-166.

Engelfriet CP, Reesink HW, Pietersz RN, Schwartz DW, Mayr WR, Blajchman MA, Goldman M, Decary F, Sher G, Georgsen J, Sprogoe-Jakobsen U, Kekomaki R, Kuhnl P, Seitz R, Maniatis A, Pinter J, Baroti K, Shinar E, Rebulla P, Greppi N, Sirchia G, Faber JC, Flanagan P, Brand A, Letowska M, Nel T, Argelagues E, Martin-Vega C, AuBuchon JP, Williamson L, Wallington T. Universal leucocyte-depletion of blood components: cell concentrates and plasma. Vox Sanguinis. 2001 81: 56-77. 
Evans RJ, Gordon JL. Proceedings: Refractoriness in blood platelets: effect of prior exposure to aggregating agents on subsequent aggregation responses. British Journal of Pharmacology. 1974. 51: 123 .

Fairbanks VF, Ziesmer SC, O'Brien PC. Methods for measuring plasma hemoglobin in micromolar concentration compared. Clinical Chemistry. 1992. 38: 132-140.

Gomez-Arbones X, Pinacho A, Ortiz P, Macia J, Gallart M, Araguas C, Sanchez JM, Teixido M. A simple flow-cytometric method for absolute counting of residual white blood cells in leukocytereduced packed red cells. Vox Sanguinis. 1999. 76: 64-65.

Guidances B. Guidance for Industry: Pre-Storage Leukocyte Reduction of Whole Blood and Blood Components Intended for Transfusion. Center for Biologics Evaluation and Research. 2012.

Herzig RH, Herzig GP, Bull MI, Decter JA, Lohrmann HP, Stout FG, Yankee RA, Graw RG, Jr. Correction of poor platelet transfusion responses with leukocyte-poor HL-A-matched platelet concentrates. Blood. 1975. 46: 743-750.

King KE, Shirey RS, Thoman SK, Bensen-Kennedy D, Tanz WS, Ness PM. Universal leukoreduction decreases the incidence of febrile nonhemolytic transfusion reactions to RBCs. Transfusion. 2004. 44: 25-29.

Kwon SW. Analysis of Important Factors Influencing the Filtration Efficiency of Bedside Filter for Leukocyte Removal. The Korean Journal of Blood Transfusion. 1995. 6: 207-216.

Lane TA, Anderson KC, Goodnough LT, Kurtz S, Moroff G,
Pisciotto PT, Sayers M, Silberstein LE. Leukocyte reduction in blood component therapy. Annals of Internal Medicine. 1992. 117: 151-162.

Menitove JE, McElligott MC, Aster RH. Febrile transfusion reaction: what blood component should be given next? Vox Sanguinis. 1982. 42: 318-321

Saarinen UM, Kekomaki R, Siimes MA, Myllyla G. Effective prophylaxis against platelet refractoriness in multitransfused patients by use of leukocyte-free blood components. Blood. 1990. 75: 512-517.

Vamvakas E. The case against universal white blood cell reduction. ISBT Science Series. 2006. 1: 64-72.

Vamvakas EC, Blajchman MA. Universal WBC reduction: the case for and against. Transfusion. 2001. 41: 691-712.

Yazer MH, Podlosky L, Clarke G, Nahirniak SM. The effect of pre-storage WBC reduction on the rates of febrile nonhemolytic transfusion reactions to platelet concentrates and $\mathrm{RBC}$. Transfusion. 2004. 44: 10-15.

http://dx.doi.org/10.15616/BSL.2017.23.2.111

Cite this article as: Shin GS, Kim BH, Kim SH, Rhee KJ, Kim YS. Comparison of Efficiency between Prestorage and Post-storage filtration by Leukoreduction Blood Filter. Biomedical Science Letters. 2017. 23: 111117. 